\title{
Developing of a 3D Printer to Produce Parts Using Powder Metal
}

\author{
Suhad Kamal Faraj \\ Department of Automated Manufacturing Engineering, Al-Khwarizmi Engineering College, University of \\ Baghdad \\ Al-Jadriya campus, Baghdad, 10071, Iraq \\ Maher Yahya Salloom \\ Department of Mechatronics Engineering, Al-Khwarizmi Engineering College, University of Baghdad \\ Al-Jadriya campus, Baghdad, 10071, Iraq \\ Enas Abd-alkarim Khalid \\ Department of Automated Manufacturing Engineering, Al-Khwarizmi Engineering College, University of \\ Baghdad \\ Al-Jadriya campus, Baghdad, 10071, Iraq
}

\begin{abstract}
The additive manufacturing (AM) process or three-dimensional printing (3DP) process is making stereoscopic shapes using a layered system. There are several materials used for printing such as plastic, wood, metal as powder, filament, liquid, or others and there are also different ways for printing. Recently, the focus has been on metal printing, but the problem is that the high energy used such as laser, electron beam, or high heat to melt the metal to print it as required. For this reason, the price of 3D printers for metal is very expensive. In this paper, design and implementation of a 3D printer for metal parts production are worked. The work also includes making an experimental test for the new 3D printer and printing 3D metal parts without using heat. In this work, TevoTarantula 3D printer has been modified in terms of software and hardware. Two new extruders are designed to inject the metal powder and adhesive, where the heat was removed from the extruder head and the printer bed. The metal powder extruder contains a powder reservoir, glass funnel, and access valve where controlled through the solenoid valve. The adhesive extruder is controlled using a simple hydraulics. The printing process was done by printing two layers of metal powder and a layer of adhesive depending on the desired shape to create 3D objects using the SolidWorks software.Different metal models were printed and these models were compared with the original design which was drawing by SolidWorks software. The difference between the actual model drawing and the printed parts is differences between $(0.004 \mathrm{~mm})$ for some parts to $(2.3 \mathrm{~mm})$ for other parts or the percentage of error is between $(0.1 \%-4 \%)$ for the printed parts. However, the material can be used in high temperatures, where rubber materials cannot be used, and in applications requiring porosity.
\end{abstract}

Keywords: 3D printer, powder metal, adhesive, layered system, FDM.

DOI: $10.7176 /$ ISDE/10-5-02

Publication date:June $30^{\text {th }} 2019$

\section{Introduction}

3D Printing, or so-called Additive Manufacturing (AM), indicates operations utilized to make 3D parts. The parts are printed using the layered system. The part is slicing into a number of layers by software in Personal Computer (PC) control [1]. Stereolithography (STL) is one of the most widely recognized types of documents that 3D printers can handle. In contrast, materials extracted in conventional processing, 3D printing, or AM make a 3D part of the Computer-Aided Design (CAD) pattern or AMF document by gradually adding the material layer to the layer [2]. The fundamental zones in this operation vary are the technologies utilized as a part of the process and the materials. Several of the various kinds of processes incorporate extrusion, light polymerized, continuous liquid binder fabrication and powder bed [3].

Each one of the 3D printing operations contains features and defects, so any type of the sort of 3D printer selected for an application often times depend upon the materials to be utilized and how the layers in the completed item are bonded. There are seven most usually utilized additive manufacturing technologies [4]:

1. Binder Jetting

2. Sheet Lamination

3. Directed Energy Deposition

4. Powder Bed Fusion

5. Material Extrusion

6. Material Jetting

7. Vat Photo-Polymerization

The first four types are currently used in metal printing, but the other three types are not applied to metal 
technologies. The material extrusion method (Fused Deposition Modeling) is used in this project to print metal parts.

FDM is the most widely recognized 3D printing strategy utilized as a part of PC 3D printing. It uses thermoplastic wire for the printing, where the wire is warmed and ejected through the printer head and builds the $3 \mathrm{D}$ objects by a layered system. The head of the printer moves in two directions (X-Y) while the Z-direction is driven by the movement of the heated bed. Effectively, the part is constructed from the base and rises up, as shown in figure 1.

FMD technology does not require dissolvable material. It can be done in such a way with ease and flexibility in processing materials, as well as does not require high experience. The utilization of a filament material additionally decreases its living arrangement time in the warming chamber and permits nonstop generation without the need of supplanting [5].

A 3D printer has been studied and developed by researchers like Santos et al. [6] presented the different research where a focus placed on the fabricating of metal parts using various laser techniques such as selective laser sintering and selective laser melting, as well as the use of different commercial machines. They proved that it is possible to produce high-intensity metal parts with perfect mechanical properties utilizing the layered fabricating with laser-based technicality. Schurig [7] concentrated on FDM because it is easy to use especially in offices and the cleanest method to print a part. Another advantage of FDM is the utilization of environmentally friendly and mechanically steady, printable material. Jaksic et al. [8] depicted an implementation of cheap, secure, experiential and open source 3D printer (Mini Metal Maker). It is used the metal clay for printing and utilizes in engineering laboratories to print bronze parts. After printing, metal clay parts were dried and then fired in a small digital kiln. The system of this printer is based on FDM. Hunko and Payton [9] developed Wire 3D (Wir3D) printing process (greatly inexpensive) using an electric circular arc to fusion metals at higher sedimentation averages than another added substance methods in metals. Wire and arc additive industrialization empowered producers to construct parts by sedimentation metal in layers utilizing welding techniques. It had been set up additive machine successfully based on the main basics and techniques of Metal Inert Gas (MIG) welding technology. Du et al. [10] presented the development of the process for new metal additive manufacturing (AM), indicated to as the Metal Fused-Coating Additive Manufacturing (MFCAM), for the consolidation of highefficiency metal parts. This method was developed precisely because of the need for high-efficiency deposition of larger metal parts. Capel et al. [11] described the utilization two AM processes, stereolithography and selective laser melting, to make multi-functional fluids gadgets with built-in interaction control ability. The eclectically laser-melting components were the initial distributed models of multifunctional 3D printed metal fluidic gadgets. These gadgets permit high temperature and pressure which should be present in solvents systems destroyer for the most gadgets made by stereolithography, polymer jetting and fused deposition modeling operations. Murr and Johnson [12] showed the over thirty years of improvement of metal droplet era for precision additive fabricating implementations using progressing, high-temperature metals and alloys. Utilizing multi-wire metal and alloy group 3D droplet printers, product functionality could be treated in the incorporated industrialization process taken advantage of rapid-speed and multi-metal 3D printing. Wire feed system frugally could be worked at minimizing material cost, decrease refuse, semi-net shape production, decreased or disposed of tooling, and product characteristics and performance improvement through microstructure control.

Until now, some researchers focused on printing different materials using a specific printing method and measurement of mechanical properties and the comparison of properties. Most researchers had focused on using new methods or developing old ways to print metals and their alloys. Few researchers focused on the software used in printers and developed.

As illustrative previous researches, metals printing need high energy or high temperature using laser, electron beam or melt the metal to be printed, and if printed in other ways, printed parts put in the oven for several hours to treat the piece. As well as, the high prices for metal printers which are currently (from $\$ 100,000$ to $\$ 500,000$ ), due to the use of different heating technologies. Thus, the objectives of this work are designing a 3D printer for metal parts production, implementation and make an experimental test for new 3D printer, and printing 3D metal parts without using heat.

\section{Material and Method}

In this project, iron metal and cyanoacrylates adhesive are used as a raw material to print 3D parts. Iron powder has various utilizations. The molecule sizes differ somewhere in the range of 20-200 $\mu \mathrm{m}$, as shown in figure 2 . The iron properties vary contingent upon the generation strategy and history of a particular iron powder [13].

Cyanoacrylates are within a group of solid quick acting adhesives with mechanical, therapeutic, and home uses. Cyanoacrylate adhesives are occasionally recognized nonexclusively as immediate glues, strength glues or super glues (albeit "Super Glue" is a commerce name). It is liquid matter as shown in figure 3. Generally, it is an acrylic sap that quickly polymerizes within the existence of water (particularly hydroxide ions). It is used thinly, to guarantee that the response continues quickly to bond. They don't fill spaces, not at all like epoxies, and light 
layer affixes more efficiently than a thick layer that does not treat appropriately [14].

\subsection{Research Approach}

This project was based on the basics of the work of 3D Tevo-Tarantula (Prusa i3) printer, as shown in figure 4, where this printer works on the FDM system. For the printer was modified to print the metal parts, the solid metal structure, stepper motors, and MK3 heated bed are used from the Tevo tarantula 3D printer. Furthermore, the new parts that are used are: a push tubular solenoids valve, a glass funnel, check valve, a nozzle with $1 \mathrm{~mm}$ diameter, a simple hydraulic system using syringe and water, and other new parts designed and printed for a new design of 3D printer details are given later. Arduino Mega 2560, a shield for a 3D printer, and stepper motor driver are used for controlling the $3 \mathrm{D}$ printer. The primary materials use powder metal and adhesive to print the parts.

\subsection{Mechanical Design}

On the basis of the used printer, which works on the FDM system, also depending on the metal powder and the used adhesive, it is designed new extrusion systems for printing metal powder and adhesive with layered systems easily.

\subsubsection{Metal Powder Extruder:}

The first option chosen for the design of the new extruder is the access valve, as shown in figure 5, which works as a check valve system, allowing the material to pass through it in one direction when the force (weight) is placed on the spring located in the middle of the valve. After practical experiments, the total springing stroke is approximately $3 \mathrm{~mm}$ and the force (weight) to open the spring is $10 \mathrm{~N}(1 \mathrm{~kg})$.

After that, a nozzle was selected, as shown in figure 6, It is suitable for crossing the metal powder through it where contains a $1 \mathrm{~mm}$ hole. When experiment the smaller nozzle openings, the powder cannot pass smoothly and close the nozzle opening.

For the powder to reach the passage area through the access valve, a glass funnel was selected. As explained previously, the access valve needs a force (weight) to open the spring, so the solenoid push shown in figure 7, is chosen to do this task.

To set up the solenoid over the glass funnel, a special holder is designed. It is contains two holes in the bottom. One of the holes is for the passage of the solenoid stick and the second is for the placement of a plastic tube through which the metallic powder comes from the external reservoir which is also as a funnel-shaped to drop the powder into the tube easily. For the purpose of protecting the glass funnel from external conditions and for the connecting it to the solenoid holder, the funnel holder is designed. A clamp is used to attach the solenoid holder to the glass funnel holder. To fix the new extruder with the X-axis, two new pieces were designed. The first was directly connected to the acrylic part that is moved by the $\mathrm{X}$-axis stepper motor as shown in figure 8 .

The second piece is designed to support the whole new extruders for not falling or tilting during the movement of the $\mathrm{x}$-axis through the printing process, as shown in figure 9.

\subsubsection{Adhesive extruder:}

A simple syringe pump was designed to push adhesives. The parts are designed and printed with a (PLA) material. The first part is to connect with the stepper motor. The second part is to connect the lead screw with the nut to be pushed the syringe. The third part is to fix the system on the wooden base through two screws and catch the syringe. The first syringe $(20 \mathrm{ml})$ of the original system was attached to a second syringe of the same size by a plastic tube and filled one syringe with water to act as a simple hydraulic system while pushing the syringe by the stepper motor. All the parts used are shown in figure 10.

A new part is designed to hold the second syringe with the third small syringe $(3 \mathrm{ml})$ in opposite directions where the small syringe is filled with the adhesive material and it is pushed by the large second syringe. At the end, a special syringe needle was used with a $(1 \mathrm{~mm})$ hole to do the work of the nozzle. By the calculation of the amount of fluid flow by two different syringes $(3 \mathrm{ml}-5 \mathrm{ml})$, it was noted that the lower the size of the syringe, the less the amount of the adhesive was exited from the head of the extruder, as illustrated in Table 1.

\subsection{Printer Assembly}

The 3D printer modification and assembling was started with the aid of the newly designed parts. The new extruders, described previously, are installed. The 3D printer appears in the final shape in figure 11. All steps of the 3D printer metal procedure are illustrated in figure 12.

\subsection{Controlling of $3 D$ printer}

The 3D printer is controlled using Repetier-Host as a program interface and is controlled by Marlin Firmware. Initially, many of the steps in Marlin's firmware have been modified, such as:

(1) Adjusting the dimensions of the 3D printer being used.

(2) Selecting the number of extruders.

(3) Adjusting the distance of the head of each extruder from the zero point and from the other extruder. 
(4) Adjusting the temperature range with the lowest temperature at $5{ }^{\circ} \mathrm{C}$ and the highest temperature at $250{ }^{\circ} \mathrm{C}$.

(5) Adjusting the motor speed for the extruders and the three axes $(\mathrm{x}, \mathrm{y}, \mathrm{z})$.

(6) Adjusting a minimum temperature for the extruder at $15^{\circ} \mathrm{C}$, where this option prevents extrusion if the temperature is below than $15^{\circ} \mathrm{C}$.

Apart from controlling the printer by Marlin firmware, there are steps that can be changed to print an individual piece such as the print speed and the number of extruders used, through the printer settings window in the Repetier-Host interface.

Several important commands are controlled by the CuraEngine slicing program, such as:

(1) Filling density

(2) A thickness of each layer

(3) A thickness of the top and bottom of the piece

(4) Infill pattern

(5) Filament diameter (the diameter of the nozzle hole)

(6) Print and bed temperature

\section{Results and Discussion}

After several attempts and corrections such as the deletion of the basic part and its framework from printing and also determining the number of layers of powder metal and the number of layers of adhesive where it is noted that in the printing of two layers of powder metal and one layer of adhesive, the result is better than if the printing in equal layers of the materials.

As shown from figure 13 to figure 16, The difference between the actual model drawing and the printed parts is differences between $(0.004 \mathrm{~mm})$ for some parts to $(2.3 \mathrm{~mm})$ for other parts or the percentage of error is between $(0.1 \%-4 \%)$ for the printed parts. The main reason for this difference is the printer's lack of precision since when it prints plastic parts (before modification); there is a difference of $(1 \mathrm{~mm})$ between the printed piece and the original model. It was also noticed that the larger the height of the piece, the greater the error rate.

\section{Conclusion}

A 3D printer for metal has designed and implemented, as it is simple and inexpensive compared to 3D printers for metals currently used in factories. The metal parts were printed in layers (FDM) system successfully, where printing two layers of metal powder and a layer of adhesive and without the use of heat. Similar 3D objects have obtained for the drawn pieces by SolidWorks.

In the future: it is possible to work on a 3D printer with higher efficiency to print more precise parts, and it is better to make a special software for this printer to be able to work without any temperature limit, where the current program should use heat sensors (thermocouple) to measure the temperature, but we can control the lowest possible temperature through which the $3 \mathrm{D}$ printer works.

\section{References}

[1] S. M. Adil, A. R. Chhapra, S. Junaid, and K. Nehal, "3D Printer," Kaisekar Technical Campus, New Panvel, Students of final year electrical 2016.

[2] B. S. Shahi, "Advanced Manufacturing Techniques(3D Printing)," International Journal of Mechanical And Production Engineering, vol. 4, no. 4, pp. 16-23, April 2016.

[3] C. S. Lee, S. G. Kim, H. J. Kim, and S. H. Ahn, "Measurement of anisotropic compressive strength of rapid prototyping parts," Journal of Materials Processing Technology, pp. 627-630, 2007.

[4] ASTM International, "Standard Terminology for Additive Manufacturing Technologies," MIT Libraries, United States, sep 2013.

[5] I. Zein, D. W. Hutmacher, K. C. Tan, and S. H. Teoh, "Fused deposition modeling of novel scaffold architectures for tissue engineering applications," Biomaterials, vol. 21, pp. 1169-1185, June 2001.

[6] E. C. Santos, M. Shiomi, K. Osakada, and T. Laoui, "Rapid manufacturing of metal components by laser forming," International Journal of Machine Tools \& Manufacture, vol. 46, pp. 1459-1468, 2006.

[7] F. Schurig, "Slicing Algorithms for 3D-Printing," Technische Universitat Munchen, Munchen, B.Sc. Computer Science student 2015.

[8] N. Jaksic, N. D’Angelo, and G. Vig, "Inexpensive Metal 3D Printers in Engineering Education:The Revolution Continues," in ASEE Rocky Mountain Section Conference, Cedar City, UT, 2016.

[9] W. S. Hunko and L. N. Payton, "Development of Wire 3D (Wir3D) Printing Parameters," in Proceedings of the ASME 2016 International Mechanical Engineering Congress and Exposition (Advanced Manufacturing), Phoenix, Arizona, USA, p. 8, 2016.

[10] J. Du , X. Wang, H. Bai , G. Zhao, and Y. Zhang, "Numerical analysis of fused-coating metal additive manufacturing," International Journal of Thermal Sciences, vol. 114, pp. 342-351, January 2017.

[11] A. J. Capel et al., "3D printed fluidics with embedded analytic functionality for automated reaction 
optimisation," Beilstein Journal of Organic Chemistry, vol. 13, pp. 111-119, January 2017.

[12] L. E. Murr and W. L. Johnson, "3D metal droplet printing development and advanced materials additive manufacturing," Journal of Materials Research and Technology, vol. 6, no. 1, pp. 77-89, March 2017.

[13] Central Drug House, "IRON FILINGS ABOUT 100 MESH," Central Drug House (P) Ltd., New Delhi, Product specification 2016.

[14] E. M. Petrie, Handbook of Adhesives and Sealants, 2nd ed. United States of Amireca: McGraw Hill Professional, 1999.

Table 1.Liquid Flow by Two Different Syringes

\begin{tabular}{|c|c|c|c|}
\hline Syringe Size $(\mathrm{ml})$ & Total Liquid $(\mathrm{ml})$ & $\begin{array}{c}\text { Total Time of } \\
\text { Discharging }(\mathrm{sec})\end{array}$ & $\begin{array}{c}\text { Discharge Liquid in } \\
\text { Second }(\mathrm{ml} / \mathrm{sec})\end{array}$ \\
\hline 3 & 2.6 & 335 & 0.00776 \\
\hline 5 & 4.5 & 333 & 0.0135 \\
\hline
\end{tabular}

These amounts were calculated under the same speed and pushed by the same syringe $(20 \mathrm{ml})$

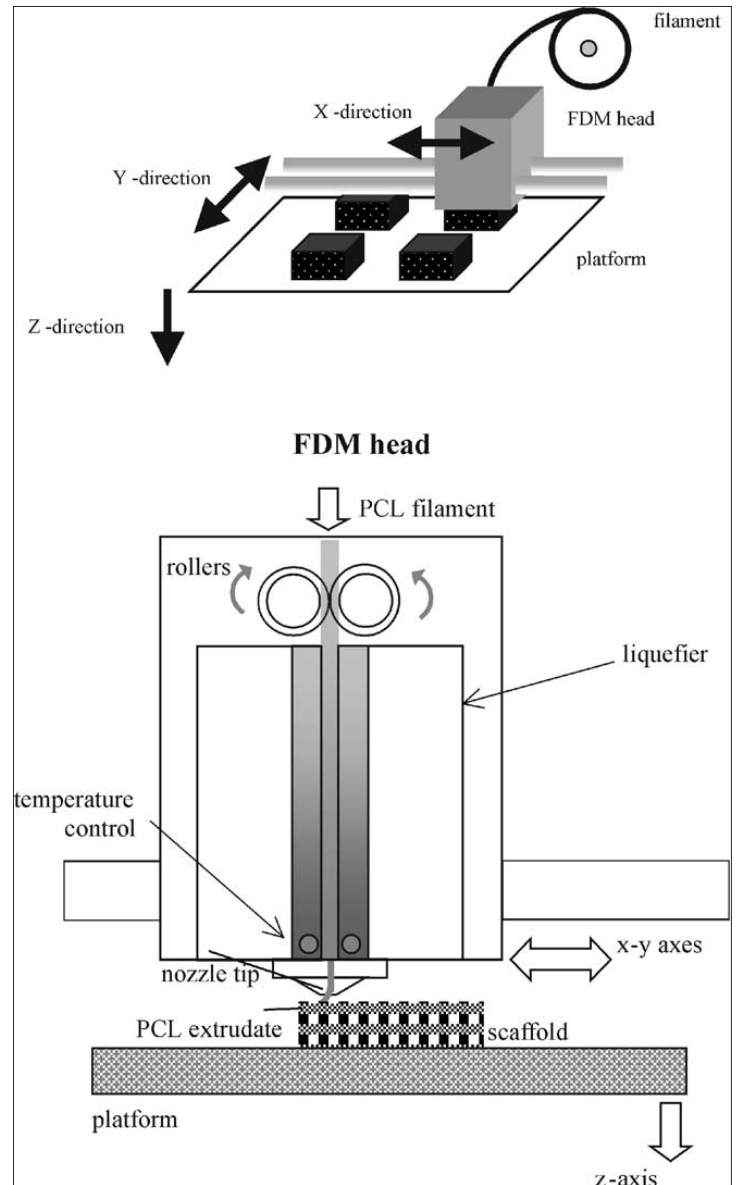

Figure 1.A schematic diagram of the FDM extrusion and deposition process [5]

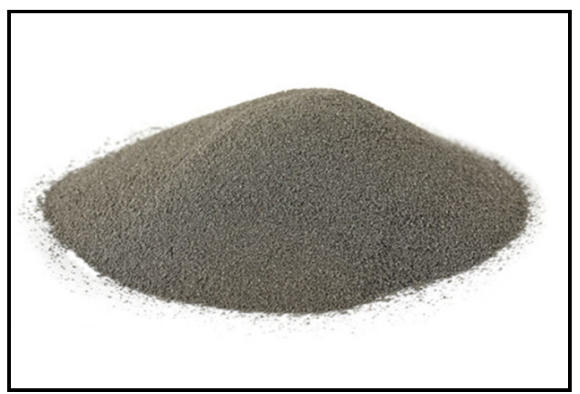

Figure 2.Iron Powder about 100 mesh (about $150 \mu \mathrm{m})$ 


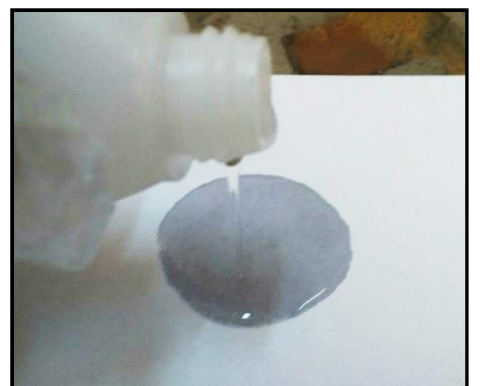

Figure 3.Cyanoacrylates adhesive

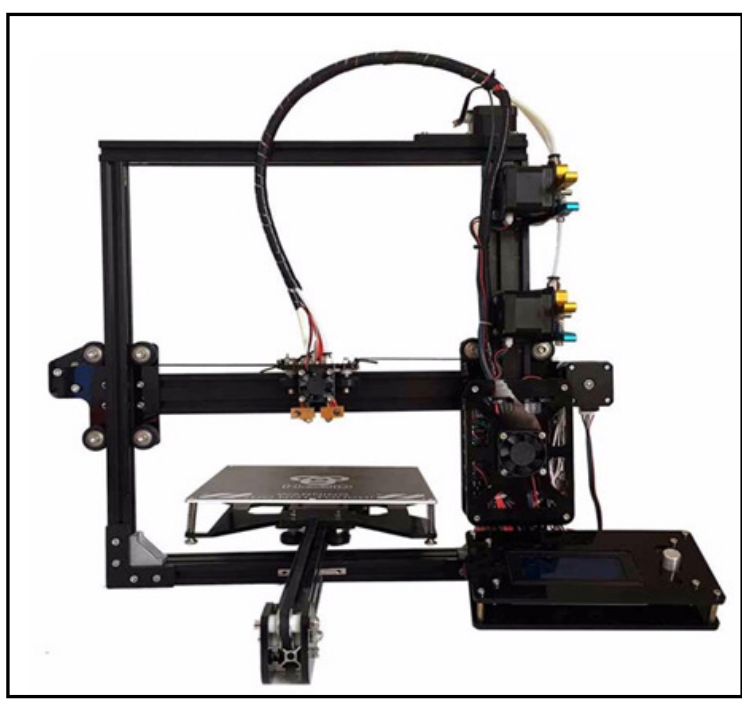

Figure 4.Tevo-Tarantula (Prusa i3) 3D printer

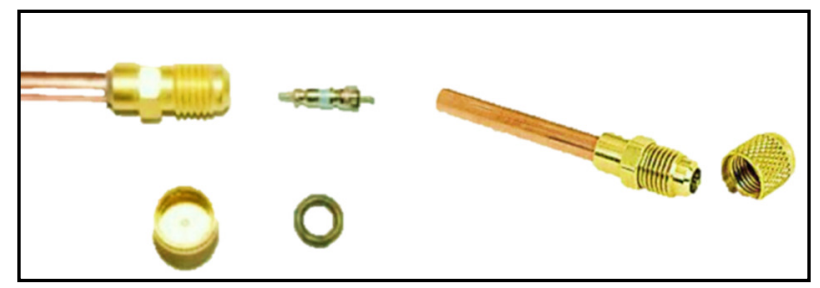

Figure 5.Access valve

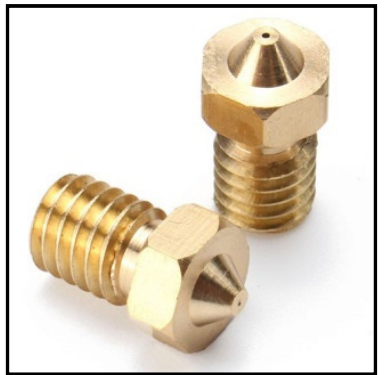

Figure 6.Nozzle of 3D printer 


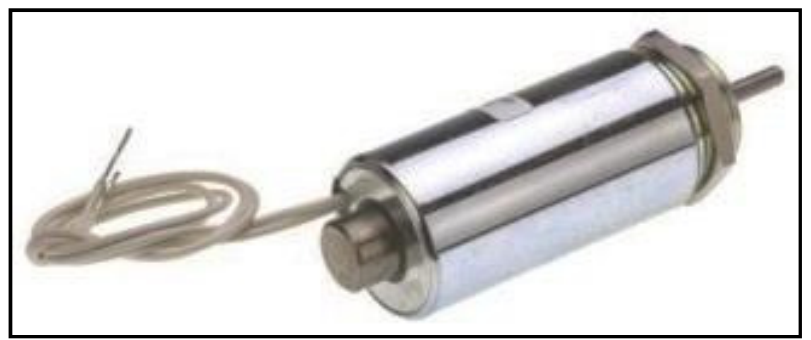

Figure 7.Push Tubular Solenoids

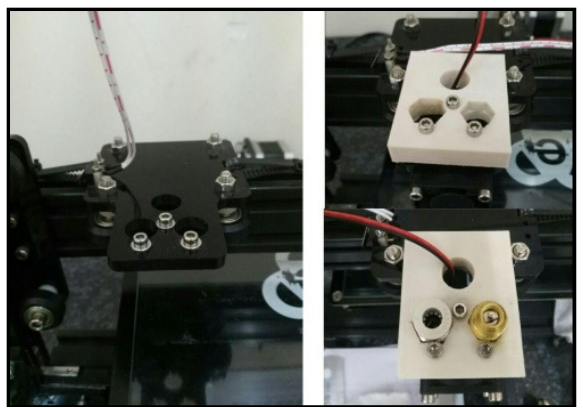

Figure 8.Connecting the extruders holder with the acrylic part

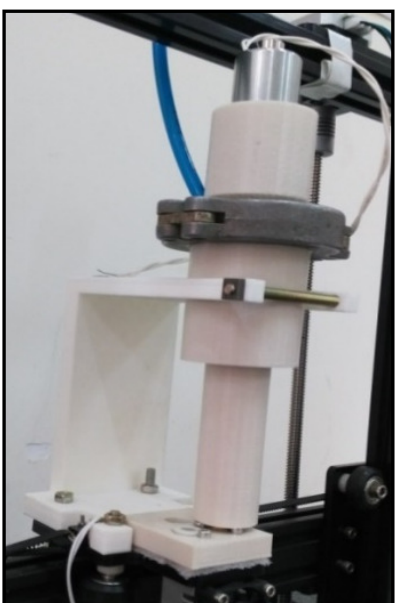

Figure 9.Connecting the powder extruders support with the acrylic part

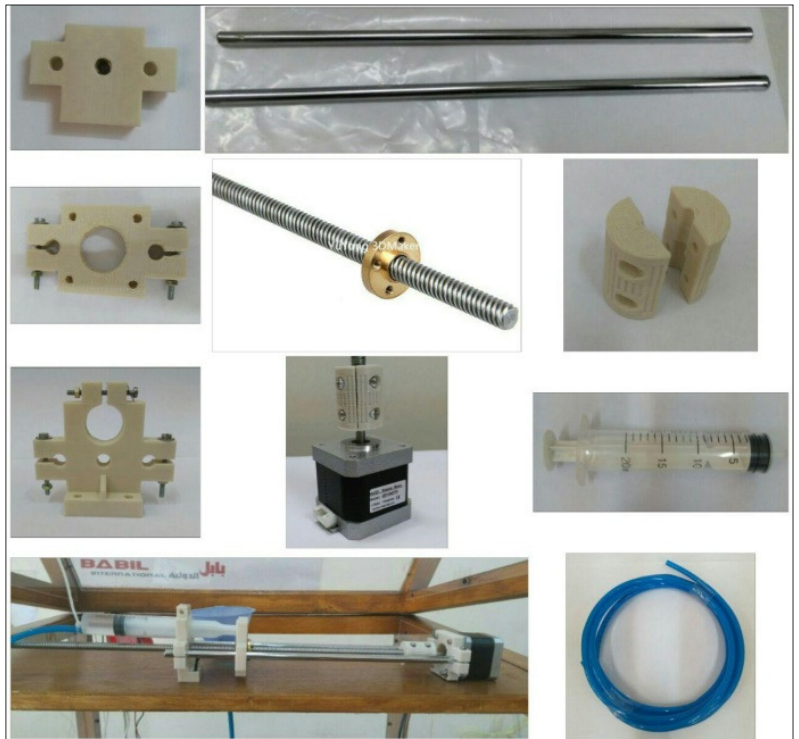

Figure 10. All top parts of adhesive extruder 


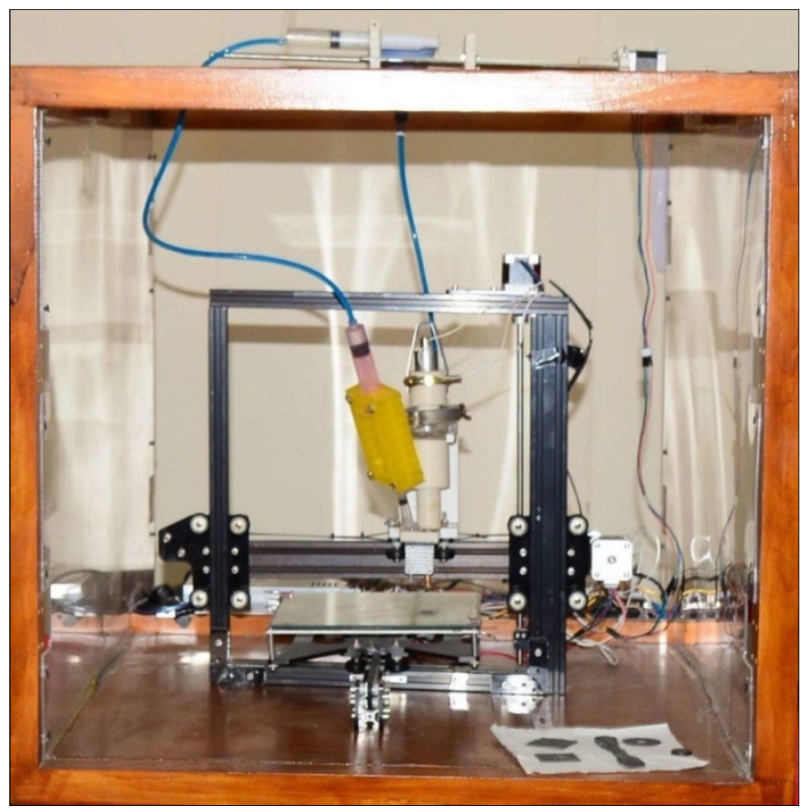

Figure 11. Final shape of the 3D printer

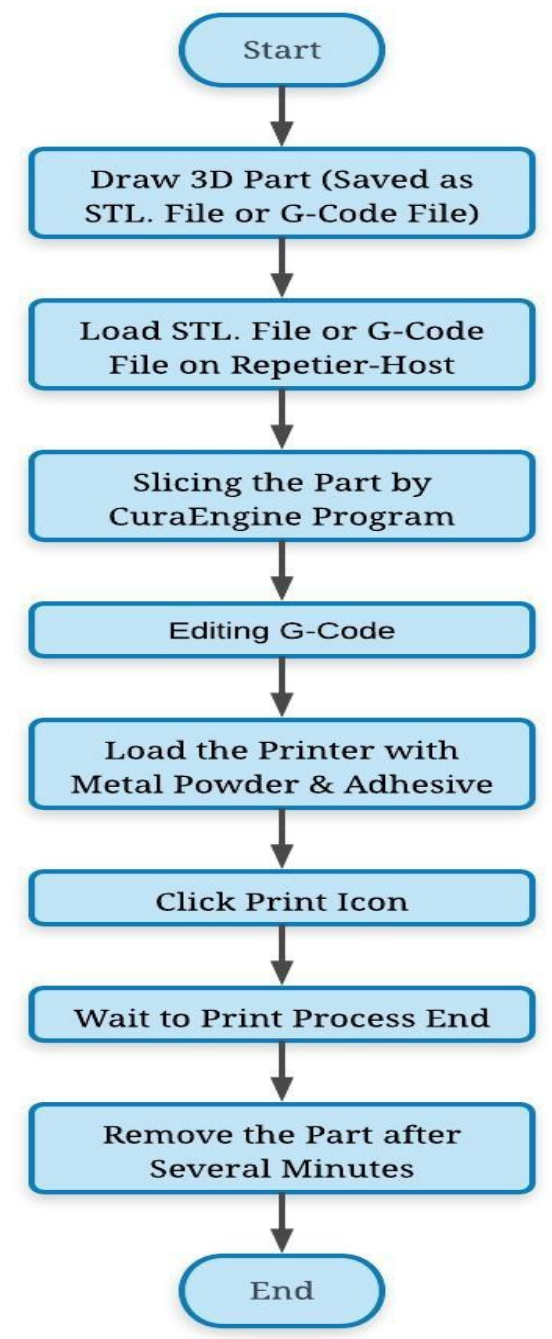

Figure 12. Flowchart of 3D printer of metal procedure 


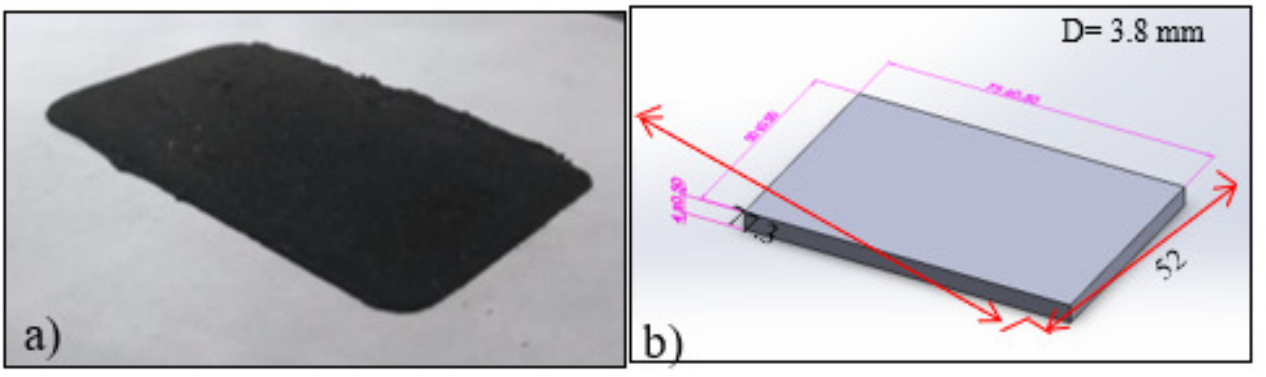

Figure 13.Rectangular Shape, a) Solidworks Drawing, b) Printed Part
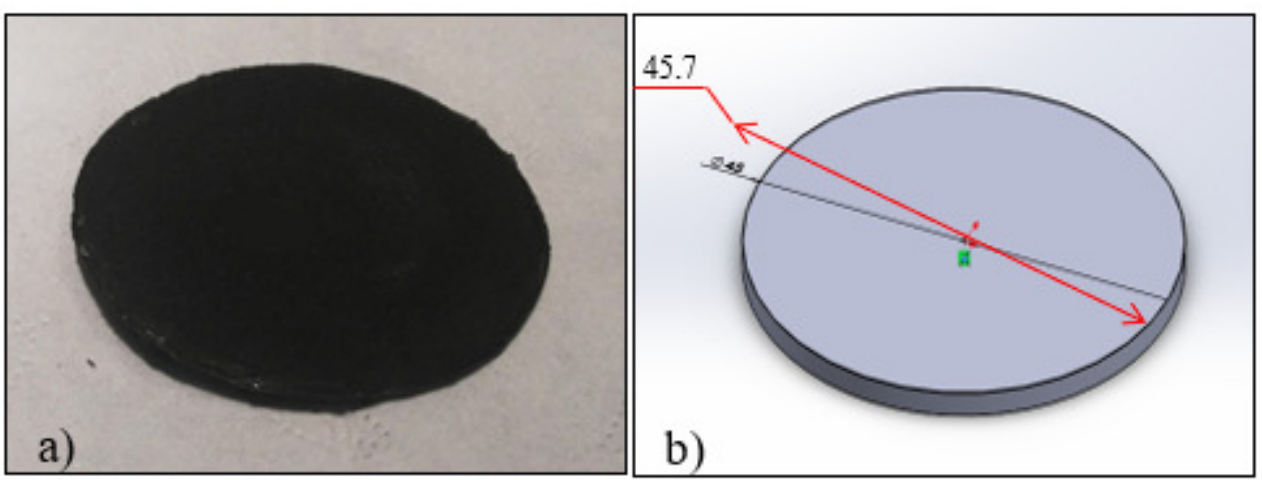

Figure 14.Circular Shape $(D=2 \mathrm{~mm})$, a) Solidworks Drawing, b) Printed Part
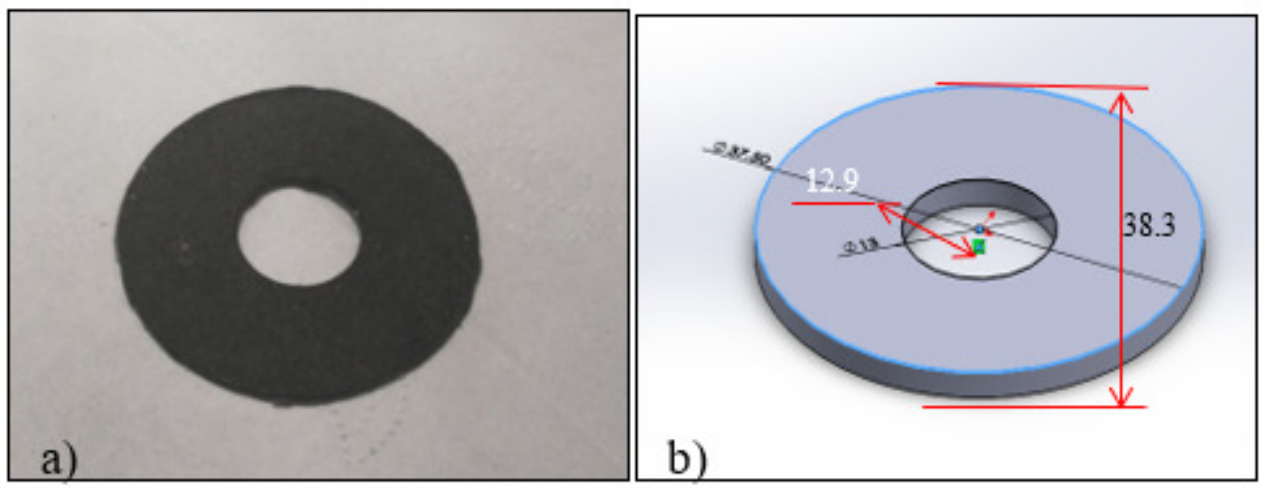

Figure 15. Washer Shape $(\mathrm{D}=1.6)$, a) Solidworks Drawing, b) Printed Part
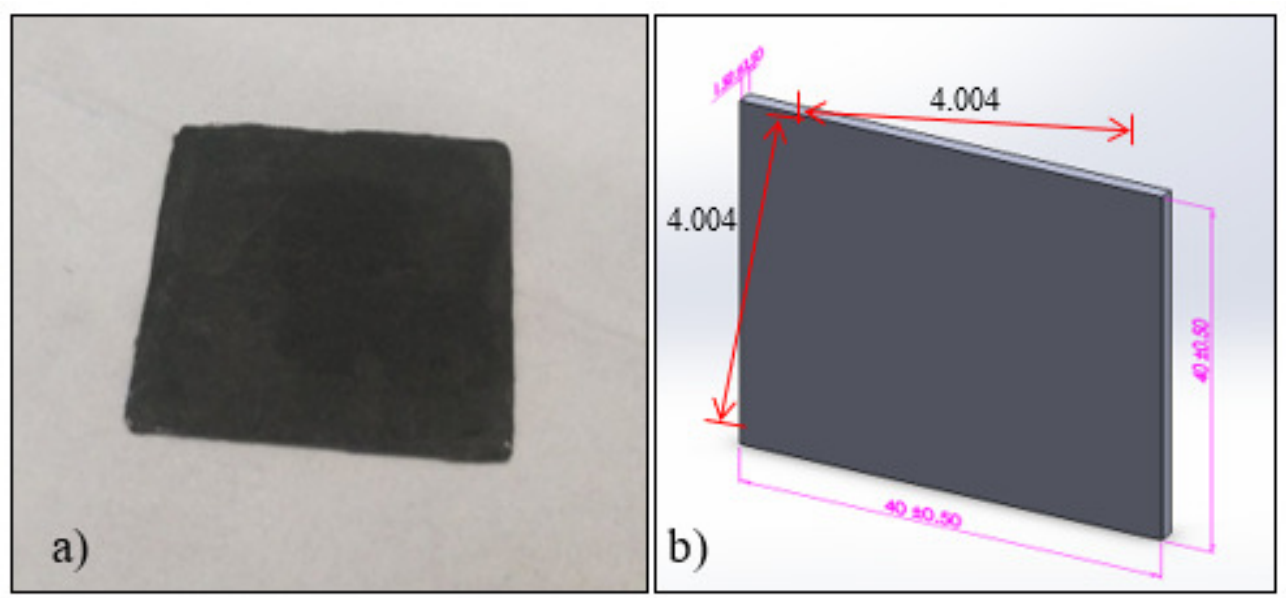

Figure 16.Cubic Shape $(D=1.5 \mathrm{~mm})$, a) Solidworks Drawing, $b)$ Printed Part 